\title{
Effect of adrenomedullin infusion on basal and stimulated aldosterone secretion in conscious sheep with cervical adrenal autotransplants
}

\author{
R Salemi, J G McDougall, K J Hardy ${ }^{\mathbf{1}}$ and E M Wintour \\ Howard Florey Institute of Experimental Physiology and Medicine, University of Melbourne, Parkville, Victoria 3052, Australia \\ ${ }^{1}$ Department of Surgery, Austin and Repatriation Medical Centre, Heidelberg, Victoria 3048, Australia \\ (Requests for offprints should be addressed to R Salemi; Email: r.salemi@hfi.unimelb.edu.au)
}

\begin{abstract}
In vivo and in vitro studies have shown conflicting effects of adrenomedullin (ADM) on the secretion of steroid hormones from the adrenal gland. While some investigators report no effect of this peptide on the output of various hormones, others have reported both stimulatory and inhibitory roles for ADM. We have shown that basal aldosterone secretion rate (ASR), in conscious sheep with cervical adrenal autotransplants, did not change when ADM was infused directly into the adrenal arterial supply. While not affecting basal ASR, ADM did produce pronounced increases in adrenal blood flow (BF). This elevation of $\mathrm{BF}$ in association with $\mathrm{ADM}$ infusion was seen in all subsequent experiments. When aldosterone output was acutely stimulated by angiotensin II (AngII), potassium chloride $(\mathrm{KCl})$ and adrenocorticotrophic hormone $(\mathrm{ACTH}), \mathrm{ADM}$ was seen to drastically reduce the
\end{abstract}

secretion of aldosterone with all agonists studied. After pre-exposure to ADM, all three agonists increased ASR but the magnitude of the responses were somewhat blunted. ADM did not have the same effect on cortisol secretion stimulated by ACTH, suggesting that the ability of this peptide to influence adrenal gland function is limited to the zona glomerulosa. In conditions of chronic elevation of aldosterone levels, such as in $\mathrm{Na}$ deficiency, ADM did not display the same inhibitory abilities seen in the acute stimulation experiments. Hence, ADM has been shown to have a direct, inhibitory role on the acute stimulation of aldosterone by AngII, $\mathrm{KCl}$ and $\mathrm{ACTH}$ while not affecting basal or chronic aldosterone secretion or cortisol secretion stimulated by ACTH.

Journal of Endocrinology (2000) 166, 389-399

\section{Introduction}

Adrenomedullin (ADM) is a recently discovered hypotensive peptide, originally isolated from human phaeochromocytomas (Kitamura et al. 1993). Subsequently, ADM transcription and translation products have been demonstrated in the adrenal medulla of several mammalian species, such as humans (Kitamura et al. 1994a), bovines (Katoh et al. 1994), pigs (Ichiki et al.1995) and rats (Sakata et al. 1994). A high concentration of ADM circulates in the blood (Kitamura et al. 1994b), suggesting a possible physiological role of ADM in the control of circulation. Human ADM is a 52-amino acid peptide with a single internal disulfide bond, which is produced as a part of the 185-amino acid pro-hormone, preproadrenomedullin (Ishimitsu et al. 1994a). Biological actions attributed to ADM include potent and sustained reduction of arterial pressure in a number of species, including rats (Ishiyama et al. 1993), sheep (Parkes \& May 1995) and humans (Lainchbury et al. 1997), as well as natriuresis and diuresis

in dogs (Ebara et al. 1994). Endocrine actions include suppression of adrenocorticotrophic hormone (ACTH) secretion from cultured pituitary cells (Samson et al. 1995).

The adrenal medulla is one of the major production sites of ADM, and like other regulatory peptides contained in adrenal medulla (for a review see Nussdorfer 1996), ADM was found to affect the secretory activity of the rat zona glomerulosa. However, its effect on aldosterone secretion remains unclear and results published to date are contradictory; it was first suggested that the actions of ADM may be dependent on the tissue preparation used. There have been reports of inhibition of aldosterone secretion in dispersed cells (Yamaguchi et al. 1995, Mazzocchi et al. 1996b, Andreis et al. 1997). On the other hand, stimulation of aldosterone secretion in rat zona glomerulosa cells (Kapas et al. 1998), adrenal slices (Andreis et al. 1997), intact capsules (Kapas \& Hinson 1996) and in the intact perfused rat adrenal preparation (Mazzocchi et al. 1996a) has been observed. Evidence indicates that ADM specifically inhibits potassium- and angiotensin II 
(AngII)-stimulated aldosterone secretion, probably by impairing $\mathrm{Ca}^{2+}$ influx (Yamaguchi et al. 1995). Mazzocchi et al. (1996b) confirmed these findings and also demonstrated that this ADM effect is mediated by subtype 1 calcitonin gene-related peptide (cGRP) receptors. In vivo, ADM has been shown to lower aldosterone plasma concentration in Na-depleted or bilaterally nephrectomised rats (Yamaguchi et al. 1996) and to suppress plasma aldosterone in sheep, despite high circulating levels of renin (Charles et al. 1997). However, no studies have examined the direct action of ADM on the adrenal gland in an in vivo situation.

In this study, sheep with a cervical adrenal autotransplant (Goding \& Wright 1964) were used to characterise: (1) the effect of ADM on basal aldosterone secretion; (2) the interactions of ADM with AngII, potassium chloride $(\mathrm{KCl})$ and $\mathrm{ACTH}$, accepted major agonists of aldosterone secretion; and (3), the effect of ADM on chronically elevated levels of aldosterone in sheep with mild $\mathrm{Na}$-deficiency, a situation where increased aldosterone secretion might be mediated, at least in part, by AngII. It is hoped that this will provide some insight into the role of ADM, and its mechanism of action in aldosterone control, and also shed some light on the mechanism of action, and role of AngII on aldosterone stimulation in conditions of $\mathrm{Na}$ depletion. An additional aim of the study is to determine whether any effect of ADM is limited solely to the zona glomerulosa or whether this peptide also has a role in influencing the function of the zona fasciculata. This question was tackled by investigating the role of ADM on ACTH-stimulated cortisol secretion.

The adrenal autotransplant preparation permits agents to be delivered directly into the adrenal arterial supply and permits the adrenal venous effluent to be collected continuously and completely without the recirculation of either aldosterone or infused agonists. This reduces interference by the extra-adrenal mechanisms regulating steroid secretion, a situation which cannot be achieved using other, more popular, in vivo techniques. In addition, this method, we believe, is more physiologically relevant than the in vitro methodologies that are currently in vogue.

\section{Materials and Methods}

\section{Animals}

Adult crossbreed Merino ewes were used in all studies. All animals were oophorectomised and had one adrenal gland completely removed to eliminate the effects of these organs on the function of the remaining adrenal gland. At the same time, cervical carotid/jugular loops were created on both sides of the animals. After a brief recovery period, all animals had a cervical adrenal autotransplant (Goding \& Wright 1964) prepared at least 6 months before experimentation to allow for recovery from surgery. Sheep were fed a diet of oaten chaff $(800 \mathrm{~g} /$ day $)$ containing
80-120 mmol $/ \mathrm{kg} \mathrm{Na}^{+}$and $270-380 \mathrm{mmol} / \mathrm{kg} \mathrm{K}^{+}$and water was offered ad libitum. All experiments were approved by the Animal Experimentation Ethics Committee of the Howard Florey Institute.

\section{General methods}

Infusions into the adrenal arterial supply were via the carotid/adrenal artery by a needle and cannula (Critchley Electrical, Silverwater, NSW, Australia; $0.58 \mathrm{~mm}$ inner diameter (ID); $0.96 \mathrm{~mm}$ outer diameter (OD)) attached to a slow infusion pump (C F Palmer Ltd, London, UK). Circulation of the infused agents was limited to the local vasculature of the adrenal transplant preparation by inflation of pneumatic cuffs (to $300 \mathrm{mmHg}$ ) around the exteriorised left jugular vein/carotid artery cranial to the adrenal and by application of finger pressure to the exteriorised jugular/adrenal vein distal to the adrenal. Cannulation of the jugular/adrenal vein (Portex Limited, Hythe, Kent, UK; $1.57 \mathrm{~mm}$ ID; 2.08 mm OD) permitted collection of adrenal venous blood. In addition, blood pressure (BP) was measured via a needle and cannula (Critchley Electrical; 1.18 mm ID; $1.70 \mathrm{~mm}$ OD) inserted into the right carotid artery and connected to a pressure transducer (Cobe, Dandenong South, Victoria, Australia; TD XIII) placed at the level of the heart. The signal from the pressure transducer was amplified and calibrated prior to each experiment against a mercury manometer. Signals were collected with a personal computer 486 data acquisition system using custom software (DT 2811 Board; Data Translation Inc., Marlborough, MA, USA) at $100 \mathrm{~Hz}$ for $10 \mathrm{~s}$ every $5 \mathrm{~min}$.

Animals were made mildly Na-depleted by cannulation of the parotid duct (Critchley Electrical; $1.18 \mathrm{~mm}$ ID; $1.70 \mathrm{~mm}$ OD) and allowing uncompensated parotid salivary $\mathrm{Na}^{+}$loss to proceed over $48 \mathrm{~h}$. The degree of $\mathrm{Na}$-depletion was estimated by measurement of salivary $\mathrm{Na}$ : K ratio in saliva samples collected before and after the $48 \mathrm{~h}$ period of parotid salivary loss.

\section{Plasma analysis}

Adrenal venous blood was collected into heparinised tubes during control and test infusions. Blood flow $(\mathrm{BF})$ was calculated from the volume of adrenal vein blood collected for each timed bleed and presented as $\mathrm{ml} / \mathrm{min}$. Samples were centrifuged for $5 \mathrm{~min}$ at 12000 r.p.m. (Biofuge A; Heraeus Septatech, Osterode, Germany) and haematocrit was read from a standard scale (Heraeus Septatech). Adrenal venous plasma was obtained by centrifugation of adrenal vein blood at 3000 r.p.m. for 5 min. Plasma [K] and $[\mathrm{Na}]$ concentrations were measured using an ionselective electrode (Synchron CX5 Clinical System; Beckman, Fullerton, CA, USA). Aldosterone concentration in extracted adrenal venous plasma was measured by radioimmunoassay (Gogerly et al. 1993). Inter- and 
intra-assay variations were 11 and $7 \cdot 8 \%$ respectively. Cross-reactivity with other steroids was $<0 \cdot 01 \%$. In each experiment, aldosterone secretion rate (ASR) was determined as a product of aldosterone concentration in adrenal venous plasma and adrenal blood flow. Plasma cortisol concentration was measured by radioimmunoassay of extracted plasma (Tangalakis et al. 1992). This assay was shown to have an intra-assay coefficient of variation of $10 \cdot 3 \%$ at $50 \mathrm{pg} /$ tube. The inter-assay variation at $30 \mathrm{pg} /$ tube was $13 \cdot 1 \%$ and $10 \cdot 7 \%$ at $200 \mathrm{pg} /$ tube. Cortisol secretion rate (FSR) was calculated in the same way as ASR. The sensitivities of both of these assays compares favourably with the double isotope dilution derivative assay, which has been validated for use with adult sheep plasma (Coghlan et al. 1966).

\section{Reagents}

Human ADM (1-52) was obtained from Bachem (Bubendorf, Switzerland). AngII-amide (Hypertensin) and ACTH (Synacthen) were purchased from Ciba Geigy (Pendle Hill, NSW, Australia). KCl was obtained from Merck (Melbourne, Australia).

\section{Experimental protocols}

Dose response effect of ADM on ASR A control infusion of $0.15 \mathrm{M} \mathrm{NaCl}$ or normal saline (NS; $22 \mathrm{ml} / \mathrm{h}$ ) was made into the adrenal arterial supply. ADM was prepared as a solution in $0 \cdot 15 \mathrm{M}$ NS and infused into the adrenal arterial supply to give concentrations of 20,2 and $0 \cdot 2 \mu \mathrm{g} / 1$ in the adrenal arterial blood flow. These translate to final concentrations of ADM in the adrenal of $4 \times 10^{-9}, 4 \times 10^{-10}$, and $4 \times 10^{-11} \mathrm{~mol} / 1$ respectively. These concentrations have been shown to produce renal blood flow changes and effects on hemodynamic parameters in conscious sheep (Parkes \& May 1995). Each ADM concentration was infused for $60 \mathrm{~min}$ in increasing order with adrenal venous blood collected at the end of each ADM infusion period $(n=6)$.

Effect of ADM infusion on acutely stimulated ASR and FSR Animals were subjected to the following treatments: (1) vehicle only $(n=4)$; (2) ADM only $(n=4)$; (3) AngII, ACTH or $\mathrm{KCl}$ agonist only $(n=4)$; (4) AngII, ACTH or $\mathrm{KCl}$ agonist only followed by a combined agonist/ADM infusion ( $n=6,5$ and 4 respectively); and (5), ADM only followed by a combined agonist/ADM infusion ( $n=6,4$ and 4 respectively). In all instances of $\mathrm{ADM}$ infusion, the peptide was given at a dose of $20 \mu \mathrm{g} / \mathrm{lBF}$ (1BF). AngII-amide was dissolved in $0 \cdot 15 \mathrm{M}$ NS and infused directly into the adrenal arterial supply to give a concentration of $0.05 \mathrm{nmol} / 1$ of AngII in the adrenal arterial supply. This rate of infusion is a maximally stimulatory dose to aldosterone secretion in vivo (BlairWest et al. 1963). ACTH (Synacthen) was dissolved in NS and infused to give a concentration of $0.02 \mathrm{nmol} / 1$ of ACTH in the adrenal arterial supply. This is a maximally stimulating concentration to aldosterone secretion in the sheep, lower rates being stimulatory only to cortisol secretion (Blair-West et al. 1962). KCl was dissolved in NS and infused at a rate calculated to increase plasma $[\mathrm{K}]$ in the adrenal arterial supply by $1 \mathrm{mmol} / \mathrm{l}$. This elevation of adrenal arterial plasma $[\mathrm{K}]$ is maximally stimulatory to aldosterone secretion in Na-replete sheep (Funder et al. 1969). A control infusion of $0 \cdot 15 \mathrm{M} \mathrm{NS}$ was made prior to each treatment as described above. For treatments 1-3, infusate was given for $60 \mathrm{~min}$ and bleeds performed at 15 , 30,45 and $60 \mathrm{~min}$ of infusion. For treatment 4, agonist was infused for $30 \mathrm{~min}$ and bleeds performed at 15 and $30 \mathrm{~min}$; this was followed with a combined agonist/ADM infusion for a further $30 \mathrm{~min}$ with bleeds taken at 15 and $30 \mathrm{~min}$ also. Treatment 5 involved a reversal of infusates to treatment 4, with ADM infused alone followed by a combined agonist/ADM infusion.

Effect of ADM infusion on chronically stimulated ASR Animals $(n=4)$ were subjected to cannulation and pre-infusions of NS and ADM prior to parotid duct cannulation in order to establish a baseline effect of ADM. An initial control infusion of $0 \cdot 15 \mathrm{M}$ NS was carried out as described above and this was followed by a 60 min infusion of ADM with bleeds taken at 30 and $60 \mathrm{~min}$. Parotid duct cannulations were then performed as described above and the animals left for $48 \mathrm{~h}$ to develop mild $\mathrm{Na}$ depletion. After this, animals were given another control infusion of $0.15 \mathrm{M} \mathrm{NS}$, and ADM was again infused for $60 \mathrm{~min}$ with bleeds taken as before. The dose of ADM infused was $20 \mu \mathrm{g} / \mathrm{lBF}$.

\section{Statistical analysis}

Results are expressed as means \pm s.e.M. One way ANOVA with repeated measures was used to determine differences within the varied treatments of the study. Significance was assumed when $P<0 \cdot 05$. Where significant differences were obtained by ANOVA, an all pairwise Bonferroni $t$-test modified for multiple comparisons was applied. Changes were considered significant at $P<0 \cdot 05$.

\section{Results}

Dose response effects of ADM on ASR and adrenal BF are shown in Fig. 1. ADM was found to have no effect on basal aldosterone secretion even at the highest dose of $20 \mu \mathrm{g} / \mathrm{lBF}$ (Fig. 1a). All values fall within the normal range of basal ASR (40-80 pmol/min). However, a significant increase in adrenal BF was observed with increasing ADM dose, with a significant difference seen at the highest dose of ADM of $20 \mu \mathrm{g} / \mathrm{lBF}$ (Fig. 1b). This is consistent with the well known vasodilatory role of this peptide. Plasma [Na] 


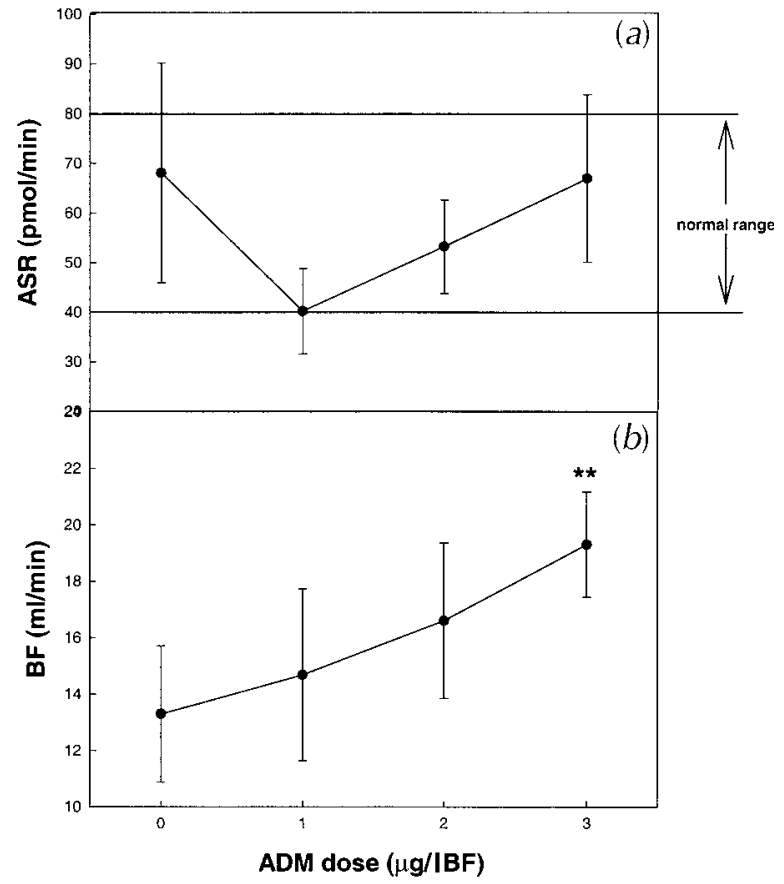

Figure 1 Dose-response effect of ADM infusion on aldosterone secretion (a) and adrenal blood flow (b). Control infusion was $0.15 \mathrm{~mol} / \mathrm{I} \mathrm{NS}$ for $30 \mathrm{~min}$. X-axis represent doses of ADM at 0 , $0 \cdot 2,2$ and $20 \mu \mathrm{g} /$ litre of BF (IBF) respectively. Normal range represents expected basal secretion of aldosterone in normal, conscious, resting animal. Values are given as the mean \pm S.E.M. $(n=6) .{ }^{*} P<0 \cdot 01$ compared with time 0 .

was also affected at this dose with its level in plasma decreasing significantly. As a result of the changes seen in the adrenal vascular bed and plasma ion levels, this dose of ADM of $20 \mu \mathrm{g} / \mathrm{lBF}\left(4 \times 10^{-9} \mathrm{~mol} / \mathrm{l}\right)$ was chosen and used in all subsequent studies.

The effect of this dose of ADM on basal aldosterone secretion was investigated further. After $60 \mathrm{~min}$ of continuous ADM infusion, no significant changes in ASR to levels above, or below, the normal basal range were seen. However, a significant stimulatory effect was again observed in adrenal BF with ADM infusion (data not shown). This significant increase in adrenal BF associated with ADM infusion was consistently seen throughout the remainder of this study. No effect of ADM infusion was seen on $\mathrm{BP}$, plasma $[\mathrm{Na}]$ or plasma $[\mathrm{K}]$ levels.

The next part of this study deals with the interaction of ADM with AngII. Infusion of normal saline vehicle (NS) alone for $1 \mathrm{~h}$ had no effect on ASR with no significant differences seen and all values falling within the abovementioned normal range (Fig. 2). No other effects of NS were seen, with all other parameters measured showing no significant change. A control AngII infusion brought about a significant, 10-fold increase in ASR after only $15 \mathrm{~min}$ and this elevated response was sustained throughout the entire $60 \mathrm{~min}$ infusion period (Fig. 2). AngII did not

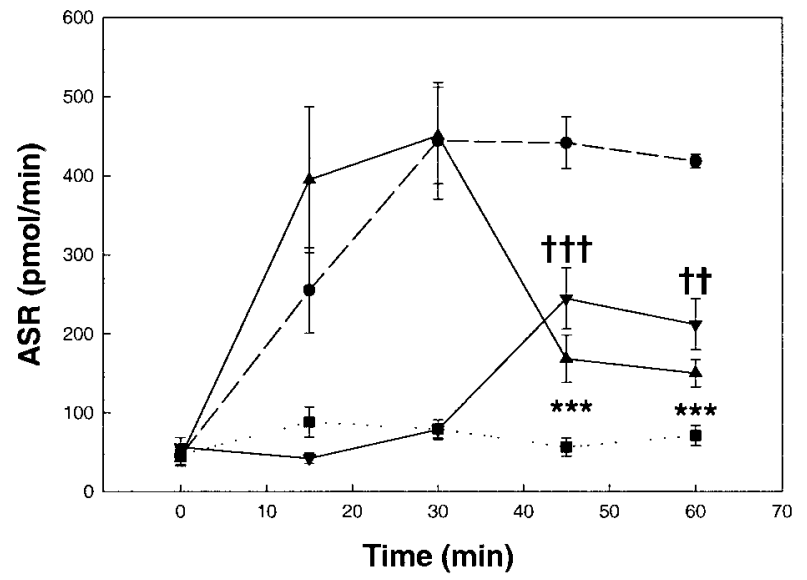

Figure 2 Effect of ADM infusion on Angll-stimulated aldosterone secretion. The following infusions were made: normal saline alone for $60 \mathrm{~min}(\boldsymbol{\square}=4)$; Angll alone for $60 \min (\boldsymbol{\square}=4)$, Angll alone for $30 \mathrm{~min}$ followed by an Angll/ADM co-infusion for $30 \mathrm{~min}$ ( $\boldsymbol{\Delta}$ $n=6$ ), and a reverse infusion of ADM alone for 30 min followed by an Angll/ADM co-infusion ( $\boldsymbol{\nabla} n=6$ ). Control infusion was $0 \cdot 15 \mathrm{~mol} / \mathrm{I}$ normal saline for $30 \mathrm{~min}$ prior to each treatment. Values are given as the mean \pm S.E.M. for each group. ${ }^{* * *} P \leq 0 \cdot 001$ compared with time $30 \mathrm{~min}$ of same treatment. ${ }^{\mathrm{t+} P} P \leq 0 \cdot 001$, ${ }^{+\dagger} P<0 \cdot 01$ compared with time 0 of same treatment.

influence BF, BP or plasma ion levels despite the big increase exerted on aldosterone secretion. The role of ADM on this stimulatory effect of AngII was studied. AngII was infused alone for $30 \mathrm{~min}$, sufficient time for this peptide to elicit its maximal stimulatory effect, and this was followed by a combined AngII/ADM infusion for a further $30 \mathrm{~min}$. AngII again produced an approximately 10 -fold increase in aldosterone secretion. When ADM was co-infused with AngII, aldosterone secretion was inhibited significantly (Fig. 2). When ASR at this time point was compared with the corresponding ASR value at the 60 min time point of AngII control infusion, an almost 3 -fold reduction in the stimulation of aldosterone elicited by AngII was observed (Fig. 2). The expected significant increases were observed in adrenal $\mathrm{BF}$ upon commencement of ADM infusion with the greatest difference observed at $30 \mathrm{~min}$ of co-infusion $(12.2 \pm 2.5 \mathrm{ml} / \mathrm{min}$ control vs $18 \cdot 3 \pm 2 \cdot 6 \mathrm{ml} / \mathrm{min} ; P<0 \cdot 01)$. BP or plasma $[\mathrm{Na}]$ levels did not change throughout the experiment. Oddly, differences were seen in plasma $[\mathrm{K}]$ levels in the different infusion periods, despite neither AngII nor ADM affecting this parameter when infused separately for longer periods in earlier studies carried out in this investigation. The period of AngII infusion brought about a drop in plasma $[\mathrm{K}]$ and, when ADM was co-infused with AngII for $30 \mathrm{~min}$, plasma $[\mathrm{K}]$ levels returned to control level. In the reverse experiment, the initial AngII infusion for $30 \mathrm{~min}$ was replaced with an ADM infusion followed by the same co-infusion of AngII/ADM. As seen previously, ADM alone had no effect on aldosterone secretion after $30 \mathrm{~min}$. 


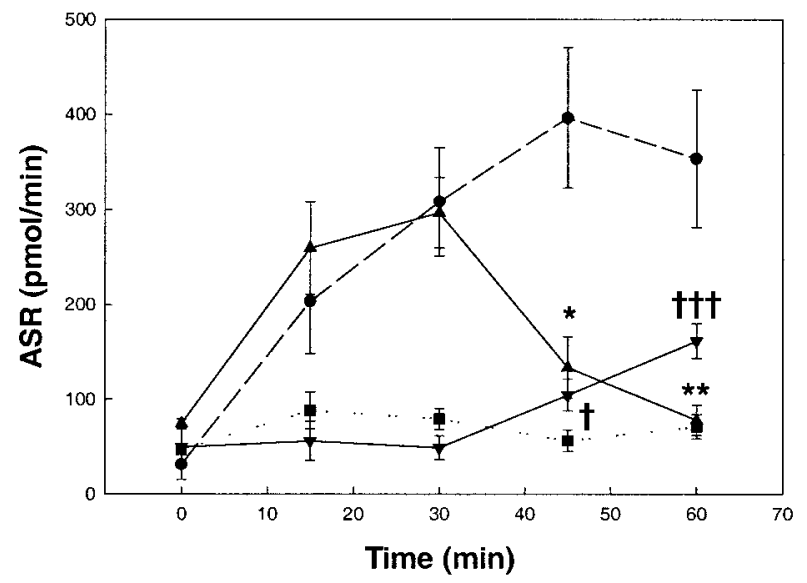

Figure 3 Effect of ADM infusion on $\mathrm{KCl}$-stimulated aldosterone secretion. The following infusions were made: normal saline alone for $60 \min (\square n=4) ; \mathrm{KCl}$ alone for $60 \min (\boldsymbol{n}=4) ; \mathrm{KCl}$ alone for $30 \mathrm{~min}$ followed by a $\mathrm{KCl} / \mathrm{ADM}$ co-infusion for $30 \mathrm{~min}(\boldsymbol{\Lambda} n=4)$; and a reverse infusion of ADM alone for $30 \mathrm{~min}$ followed by a $\mathrm{KCl} / \mathrm{ADM}$ co-infusion $(\boldsymbol{\nabla} n=4)$. Control infusion was $0.15 \mathrm{~mol} / \mathrm{l}$ normal saline for $30 \mathrm{~min}$ prior to each treatment. Values are given as the mean \pm S.E.M. for each group. ${ }^{*} P<0 \cdot 05,{ }^{*} P<0 \cdot 01$ compared with time $30 \mathrm{~min}$ of same treatment. ${ }^{\dagger} P<0 \cdot 05,{ }^{+\dagger} P<0 \cdot 001$ compared with time 0 of same treatment.

During the co-infusion ASR was seen to increase significantly (by approximately 4-fold; Fig. 2). This 4-fold increase is a somewhat blunted response when compared with the 10-fold increases elicited by AngII alone seen previously (Fig. 2). Significant increases in adrenal BF were observed throughout the total $60 \mathrm{~min}$ infusion of $\operatorname{ADM}(9 \cdot 4 \pm 1 \cdot 2 \mathrm{ml} / \mathrm{min}$ control vs $17 \cdot 8 \pm 2 \cdot 2 \mathrm{ml} / \mathrm{min}$ at 45 min; $P<0 \cdot 001)$. No significant changes in $\mathrm{BP}$, plasma $[\mathrm{Na}]$ or plasma $[\mathrm{K}]$ were observed.

The effect of ADM on KCl-stimulated aldosterone secretion was the second acute interaction investigated. A control $\mathrm{KCl}$ infusion for $60 \mathrm{~min}$ significantly increased ASR, a greater than 10-fold stimulation of aldosterone output (Fig. 3). The stimulation was significant from $30 \mathrm{~min}$ of infusion and was sustained until the end of infusion. No BF changes or changes in BP were observed with this control $\mathrm{KCl}$ infusion. $\mathrm{KCl}$ was infused at a rate calculated to increase $[\mathrm{K}]$ in adrenal arterial blood by $1 \mathrm{mmol} / \mathrm{l}$. This was achieved with a significant increase in plasma $[\mathrm{K}]$ levels compared with control throughout the entire infusion period. The increase in plasma $[\mathrm{K}]$ is concomitant with the increased aldosterone secretion. The study in which the interaction of ADM with $\mathrm{KCl}$ was investigated showed a significant increase in ASR after only $15 \mathrm{~min}$ of $\mathrm{KCl}$ infusion, with the stimulation more significant at $30 \mathrm{~min}$ (4-fold stimulation). Significant inhibition of ASR was observed with concomitant infusion of $\mathrm{KCl}$ with $\mathrm{ADM}$, with stimulation almost completely abolished by $\mathrm{KCl}$ (Fig. 3). When this is compared with the corresponding time point of the $\mathrm{KCl}$ control infusion, it is clear that ADM completely blocked the stimulation of aldosterone by $\mathrm{KCl}$ (Fig. 3). Significant changes in adrenal $\mathrm{BF}$ were observed with concomitant infusion of $\mathrm{KCl}$ and ADM. BF was observed to increase significantly, coinciding with ADM infusion, from $10 \cdot 0 \pm 0.9 \mathrm{ml} / \mathrm{min}$ at $30 \mathrm{~min}$ of infusion of $\mathrm{KCl}$ alone to $17 \cdot 1 \pm 3 \cdot 1 \mathrm{ml} / \mathrm{min}$ at $30 \mathrm{~min}$ of concomitant $\mathrm{KCl} / \mathrm{ADM}$ infusion $(P<0 \cdot 05)$. The increased BF with ADM infusion was not, however, significantly different to the control $\mathrm{BF}$ of $12 \cdot 0 \pm 1 \cdot 3 \mathrm{ml} / \mathrm{min}$. No changes in $\mathrm{BP}$ or plasma $[\mathrm{Na}]$ were evident throughout this experiment. Plasma [K] was seen to elevate significantly at $30 \mathrm{~min}$ of $\mathrm{KCl}$ infusion. The magnitude of this elevation was only $0.9 \mathrm{mmol} / \mathrm{l}$ and this explains why the magnitude of the ASR response was not as great in this experiment as it was for the $\mathrm{KCl}$ control experiment, where plasma $[\mathrm{K}]$ was raised by $1.1 \mathrm{mmol} / 1$. Despite this, plasma $[\mathrm{K}]$ remained significantly and sufficiently elevated throughout the entire experiment. In the reverse experiment, ADM alone had no effect on ASR after $30 \mathrm{~min} . \mathrm{KCl}$ stimulation of aldosterone in the adrenal gland pre-exposed to ADM was significant, with a 3-fold stimulation (Fig. 3). This was, however, only half as great as the stimulation seen with only $\mathrm{KCl}$ infused for the same amount of time (Fig. 3). Adrenal BF was significantly increased throughout the entire experiment $(10 \cdot 8 \pm 2 \cdot 4 \mathrm{ml} / \mathrm{min}$ control vs $19 \cdot 4 \pm 3.8 \mathrm{ml} / \mathrm{min}$ at $60 \mathrm{~min} ; P<0 \cdot 01)$, reflecting the continuous infusion of ADM throughout the entire $60 \mathrm{~min}$. No change in BP was seen throughout the experiment. Plasma [K] was significantly increased by $0.6 \mathrm{mmol} / 1$ at the end of concomitant $\mathrm{KCl} / \mathrm{ADM}$ infusion, leading to the stimulation of aldosterone secretion. Plasma $[\mathrm{Na}]$ was also significantly changed at $15 \mathrm{~min}$ of ADM infusion. This decrease was transient and not sustained throughout the entire experiment.

Finally, we investigated acute stimulation of ASR by ACTH. A control infusion of ACTH alone for $60 \mathrm{~min}$ elicited a significant increase in ASR after $30 \mathrm{~min}$ (Fig. 4). This infusion of ACTH produced no changes in BF, BP, plasma $[\mathrm{Na}]$ or plasma $[\mathrm{K}]$. The interaction experiment of ADM with ACTH produced an initial 10-fold increase in ASR with ACTH infusion. Upon infusion with concomitant ACTH/ADM, ASR was seen to drop significantly; again, an almost complete abolition of ASR stimulated by ACTH (Fig. 4). When this value is compared with the corresponding time point of the control ACTH infusion, the inhibitory effect of ADM becomes quite obvious (Fig. 4). Adrenal BF was increased significantly simultaneously with ADM infusion $(10.8 \pm 2.5 \mathrm{ml} / \mathrm{min}$ control vs $17.5 \pm 3.0 \mathrm{ml} / \mathrm{min}$ at $45 \mathrm{~min} ; P<0.001)$. No changes in $\mathrm{BP}$, plasma $[\mathrm{Na}]$ or plasma $[\mathrm{K}]$ were apparent throughout the entire experiment. The reverse experiment again showed an effect of ADM infusion only on basal ASR. Upon commencement of concomitant ACTH/ADM infusion, ASR was seen to increase 5 -fold at $45 \mathrm{~min}$ but again, this response is smaller than the response to ACTH 


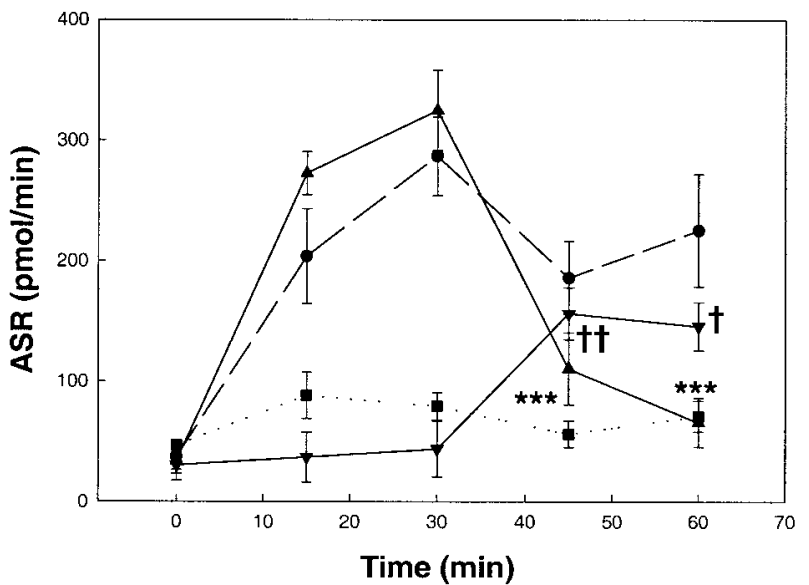

Figure 4 Effect of ADM infusion on ACTH-stimulated aldosterone secretion. The following infusions were made: normal saline alone for $60 \min (\square n=4)$; ACTH alone for $60 \min (-n=4)$; ACTH alone for 30 min followed by an ACTH/ADM co-infusion for 30 $\min (\boldsymbol{\Delta} n=5)$; and a reverse infusion of ADM alone for 30 min followed by an ACTH/ADM co-infusion $(\boldsymbol{\nabla} n=4)$. Control infusion was $0.15 \mathrm{~mol} / \mathrm{I}$ normal saline for $30 \mathrm{~min}$ prior to each treatment. Values are given as the mean \pm S.E.M. for each group. ${ }^{* * *} P<0 \cdot 001$ compared with time $30 \mathrm{~min}$ of same treatment. ${ }^{+t} P<0 \cdot 01,{ }^{\dagger} P<0 \cdot 05$ compared with time 0 of same treatment.

alone (Fig. 4). Significant increases in BF were not observed, despite it increasing from $10 \cdot 3 \pm 2 \cdot 1 \mathrm{ml} / \mathrm{min}$ at control level to $17 \cdot 1 \pm 2 \cdot 5 \mathrm{ml} / \mathrm{min}$ at $45 \mathrm{~min}$ of ADM infusion. The increased $\mathrm{BF}$ persisted throughout ADM infusion. No changes in BP, plasma $[\mathrm{Na}]$ or plasma $[\mathrm{K}]$ were observed throughout the experiment.

The effect of ADM on ACTH-induced cortisol secretion was investigated (data not shown). ACTH elicited a 6-fold increase in cortisol secretion at $45 \mathrm{~min}$ of infusion. FSR was observed to rise from $24.2 \pm 0.8 \mathrm{pmol} / \mathrm{min}$ at time 0 to a peak of $155.3 \pm 14.9 \mathrm{pmol} / \mathrm{min}$ at $45 \mathrm{~min}$ $(P<0 \cdot 001)$. The stimulation of cortisol by ACTH in the interaction experiment was of a similar magnitude. ACTH/ADM co-infusion had no effect on cortisol secretion with the secretion rate remaining significantly elevated $(129 \cdot 8 \pm 21 \cdot 4 \mathrm{pmol} / \mathrm{min}$ at $60 \mathrm{~min})$. Basal FSR was unaffected by initial ADM infusion. With concomitant ACTH/ADM infusion, FSR was increased significantly. This increase was of a similar magnitude response in cortisol output to that seen in prior experiments $(133.9 \pm 47 \cdot 4 \mathrm{pmol} / \mathrm{min}$ at $45 \mathrm{~min})$.

The role of ADM on chronic stimulation of aldosterone by $\mathrm{Na}$ depletion was investigated. Animals were determined to be sufficiently $\mathrm{Na}$ depleted when their salivary $\mathrm{Na}: \mathrm{K}$ fell to below 25. Prior to $\mathrm{Na}$ depletion, infusion of ADM for $60 \mathrm{~min}$ had no significant effect on ASR levels compared with control. ASR immediately following $\mathrm{Na}$ depletion, however, was significantly different to control (Fig. 5). This chronic stimulation of aldosterone seen with $\mathrm{Na}$-depletion is $1 \cdot 5$-fold higher than the acute stimulation

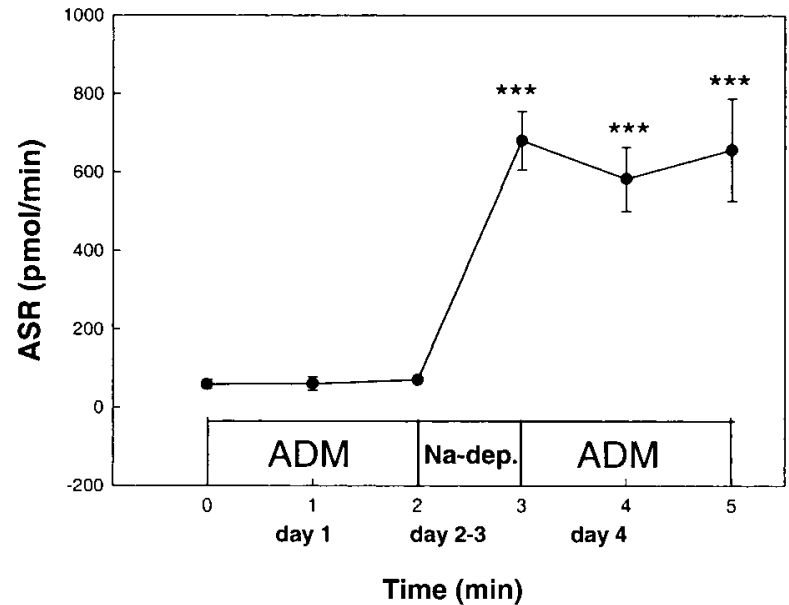

Figure 5 Effect of ADM infusion on chronic aldosterone secretion stimulated by sodium depletion. Day 1 represents an initial ADM infusion for $60 \mathrm{~min}$ to establish a baseline level of secretion, day 2-3 represents a $48 \mathrm{~h}$ period of parotid duct salivary loss to establish a state of sodium depletion and day 4 represents a further infusion of ADM for $60 \mathrm{~min}$. Control infusion was $0 \cdot 15 \mathrm{~mol} / \mathrm{I}$ normal saline for $30 \mathrm{~min}$ prior to each ADM infusion. Values are given as the mean \pm S.E.M. $(n=4) .{ }^{* *} P<0 \cdot 001$ compared with time 0 on day 1 .

seen with AngII. Infusion of ADM for 60 min directly into the stimulated adrenal gland had no significant effect on ASR, with secretion remaining very high until the end of infusion (Fig. 5). Curiously, significant differences were seen in $\mathrm{BF}$ in association with ADM infusion only on day 4 of the experiment, with $\mathrm{BF}$ rising from the control value of $10 \cdot 7 \pm 0 \cdot 9 \mathrm{ml} / \mathrm{min}$ to $17 \cdot 3 \pm 2 \cdot 7 \mathrm{ml} / \mathrm{min}$ by the end of infusion $(P<0 \cdot 05)$. On day 1 , however, a rise in $\mathrm{BF}$ was seen with ADM infusion but this change was not significant $(12.7 \pm 1.3 \mathrm{ml} / \mathrm{min}$ at $0 \mathrm{~min}$ vs $16.4 \pm 2.0 \mathrm{ml} / \mathrm{min}$ at $60 \mathrm{~min}$ ). No change in BP was observed throughout the experiment. Plasma $[\mathrm{Na}]$ decreased significantly post- $\mathrm{Na}$ depletion, as a reflection of the animals entering a condition of $\mathrm{Na}$ depletion. No changes in plasma $[\mathrm{K}]$ were seen throughout the experiment.

\section{Discussion}

The current studies were performed to investigate the role of ADM in the regulation of aldosterone secretion from the adrenal gland. The results show that ADM causes changes in the adrenal vascular bed which lead to increases in blood flow. This vasodilatory action of ADM is consistent with the findings of other investigators (Kitamura et al. 1993).

We have also shown that ADM infusion has no effect on basal secretion of aldosterone. This finding is in contrast to other studies which have reported an increase in basal aldosterone secretion (Mazzocchi et al. 1996a, Andreis 
et al. 1997). It is important to consider that the experimental approaches used by the above researchers differ to each other as well as to our methods. Intact perfused rat adrenal preparations, intact capsules and adrenal slices were used, respectively, by the above groups. It was a long-held belief that the actions of ADM may be dependent on the tissue preparation used. It was thought that ADM was inhibitory to aldosterone secretion in dispersed cells and adrenal slices, but stimulatory in intact adrenals and animals, where the integrity of the gland makes it possible for ADM to activate many possible autocrine/ paracrine mechanisms, such as release of catecholamines (for review see Vinson et al. 1985). The above idealogy was thrown into doubt recently with the finding that ADM stimulates aldosterone secretion in rat zona glomerulosa cells (Kapas et al. 1998). This anomalous observation was explained in terms of different ADM receptor subtypes which mediate different ADM effects. This is discussed in more detail below.

This is the first study to date which investigates the direct effect of ADM on an intact adrenal gland in an in vivo situation leading to results which cannot be achieved using current in vitro methods. We have shown that this peptide exerts a substantial inhibition of aldosterone secretion stimulated by AngII, $\mathrm{KCl}$ and ACTH. In addition, we also investigated the ability of the peptide to block the onset of stimulation by AngII, $\mathrm{KCl}$ and $\mathrm{ACTH}$ by pre-exposing the gland to ADM prior to agonist infusion. The normal magnitude of stimulation of aldosterone previously seen with these agonists was approximately 10-fold. This response was subdued when agonist infusion was preceded by ADM. It appears then, that pre-exposure to ADM has altered the adrenal gland's responsiveness or capacity to respond normally to all three agonists. This inhibitory effect on stimulated aldosterone has been reported by other investigators, predominantly with regard to AngII- and K-stimulated secretion (Yamaguchi et al. 1995, Andreis et al. 1997, Belloni et al. 1998a). Our finding, that ADM also acts to inhibit aldosterone secretion stimulated by $\mathrm{ACTH}$, is novel and casts doubt on the currently accepted mechanism of ADM action. This surprising result, regarding ACTH-stimulated secretion, may be attributable to differences in the methods used. No studies have been performed to date on the intact human, and of those performed on intact rats and sheep, none have been able to completely isolate the adrenal gland and look solely at the direct effects of ADM and ACTH on this organ. When these different methods are compared, differences in results are to be expected.

Since ACTH is a well known agonist for cortisol, the secretion of this steroid was measured in an effort to elucidate whether the inhibitory effect of ADM is specific to the zona glomerulosa or whether it is a general antagonist of the adrenal cortex. The results indicate that ADM fails to exert an influence on cortisol secretion stimulated by ACTH, with cortisol levels remaining elevated throughout infusion of ADM. This indicates that the inhibitory effect of ADM is limited only to zona glomerulosa cells and that this peptide does not exert an influence on the zona fasciculata. The presence of functional specific receptors (of the CGRP1 subtype) for ADM in human zona glomerulosa, but not in zona fasciculatareticularis cells (Belloni et al. 1998b), could explain why ADM affects aldosterone, but not cortisol secretion, in response to ACTH. ACTH is thought to increase glucocorticoid release by increasing $\mathrm{BF}$ in adrenals; interestingly, we saw no such elevation of adrenal BF with ACTH infusion to accompany the stimulation of cortisol. This may be an indication of an alternative mechanism for cortisol stimulation by ACTH not involving changes in the adrenal vascular bed. This mechanism may perhaps involve cAMP and/or $\mathrm{Ca}^{2+}$, known second messengers for ACTH.

A body of evidence indicates that the majority of the peptides, which are contained in the adrenal medulla, are involved in the regulation of the secretion of adrenocortical cells (Nussdorfer 1996). These regulatory peptides can affect adrenal cortex function in two ways. They may act in a paracrine manner, either by binding to specific receptors located on adrenocortical cells or by eliciting the release by chromaffin cells of other regulatory molecules, which in turn may act on adrenocortical cells. On the other hand, they may modulate one or more of the various extra-adrenal mechanisms (eg. pituitary ACTH or kidney renin release) involved in the integrated multifactorial control of the secretory activity of the adrenal cortex. Gallo-Payet et al. (1987) have reported the presence of rays containing medullary tissue extending across the cortex of rat adrenal gland by light and electron microscopy. These bring medullary cells in close proximity to cortical cells and suggest that the secretory products of the medullary cells modulate the physiological function of the adrenal cortex, possibly by a paracrine mechanism. Compelling evidence indicates that several intramedullary peptides, such as ADM, are able to influence aldosterone secretion by regulating the release of factors, which can either inhibit or stimulate aldosterone. Catecholamines, released by medullary chromaffin cells, and other $\beta$-adrenoceptor agonists can enhance mineralocorticoid secretion in rodents, bovines and humans (Nussdorfer 1996). Evidence suggests that preproadrenomedullin-derived peptides inhibit catecholamine release by these cells (Richards et al. 1996). There is also evidence that ADM stimulates catecholamine release from human adrenal medulla (Andreis et al. 1997). These findings, however, are rare, and current opinion suggests that ADM has no effect on catecholamine release. So the effect of ADM on aldosterone synthesis via an effect on catecholamine release remains questionable. A stronger case for similar scenarios can be mounted with regards to other aldosterone regulators. Such factors, known to affect aldosterone release and subject to regulation themselves by ADM, include atrial natriuretic peptide 
(ANP; Yamamoto et al. 1988, Gennari et al. 1991), arginine vasopressin (Yokoi et al. 1996), and adrenal endothelins (Kohno et al. 1995, Nussdorfer et al. 1999). What emerges most strongly from the literature, however, is the evidence that ANP, endothelin-1 and ADM are produced within the zona glomerulosa cells themselves. This suggests an autocrine as well as a paracrine role in the regulation of zona glomerulosa function and aldosterone secretion by the interaction of these factors. Also, ADM may exert its effect on the zona glomerulosa cells by causing intracellular calcium levels to rise, leading to activation of nitric oxide (NO) synthase and $\mathrm{NO}$ release. The presence of NO synthase in rat adrenal glands has been proven (Bredt et al. 1990) and an inhibitory effect of NO on aldosterone secretion has been shown (Simmons \& Freeman 1995, Natarajan et al. 1997). Recent work undertaken by this laboratory also supports a minor role for $\mathrm{NO}$ in aldosterone regulation (unpublished results) and raises the possibility that $\mathrm{NO}$ may work in concert with ADM to provide negative regulation of aldosterone secretion. The possibility that ADM may modulate mineralocorticoid secretion by interacting with other regulators of adrenal function needs to be explored.

In vivo however, the direction of blood flow through the adrenal gland is from the outer capsule into the centre, and so it is unlikely that ADM of medullary origin can reach the zona glomerulosa except via peripheral blood. Also, an endocrine mechanism might be considered in the inhibition of aldosterone secretion by ADM, because the existence of ADM in circulating blood has been reported (Kitamura et al. 1994b). The complementary DNA for an ADM receptor has been cloned from rat lung tissue (Kapas et al. 1995), and an orphan receptor gene has been identified, encoding a common CGRP1 receptor for both CGRP and ADM (Kapas \& Clark 1995). The existence of CGRP1 and/or ADM receptors in human adrenal zona glomerulosa has been proven by autoradiography (Belloni et al. 1998b). Also recently demonstrated in adrenals, the calcitonin-receptor-like-receptor (CRLR) can function as either a CGRP receptor or an ADM receptor, depending on which receptor activity-modifying proteins (RAMPs) are expressed (McLatchie et al. 1998). As mentioned earlier, in addition to tissue integrity, the effect of ADM may depend on whether it acts through the CGRP receptor or another receptor subtype (for review see Hinson \& Kapas 1998).

Until now, it has been generally accepted that ADM specifically inhibits only AngII- and K-stimulated aldosterone secretion, while not affecting basal or ACTHstimulated secretion. This led to the idea that ADM acts to block $\mathrm{Ca}^{2+}$ influx, as the mechanism of AngII- and $\mathrm{K}$-stimulated secretion involves raising intracellular calcium. The present study shows ADM inhibition of aldosterone output induced by all three agonists, and hence the possibility of a new mechanism of action. One prospect is that the locus of effect of ADM on the biosynthetic pathway to aldosterone is at a site common to all three agonists, namely on the conversion of cholesterol to pregnenolone, where ACTH, AngII and $\mathrm{K}$ all exert an influence (Aguilera \& Catt 1979). There is now general consensus on the key role played by the steroidogenic acute regulatory protein at these early steps of the biosynthetic pathway in steroid secretion induced by all three agonists (Hall et al. 1979, Clark et al. 1994). The locus of effect of ADM in the biosynthetic pathway to aldosterone might be at this early stage of proceedings, where AngII, $\mathrm{K}$ and $\mathrm{ACTH}$ are all influential.

It must be mentioned however, in contradiction to the theory that ADM inhibits aldosterone secretion, that ADM itself stimulates two signal transduction pathways; cAMP accumulation and $\mathrm{Ca}^{2+}$ mobilisation (Shimekake et al. 1995). Both these second messenger mechanisms are utilised by various factors, such as ACTH, to stimulate aldosterone secretion. Further work is required to clarify the exact mechanism of the ADM/aldosterone interaction.

Sodium depletion is the major pathophysiological stimulus to biosynthesis and secretion of aldosterone. After drastically increasing aldosterone output via mild sodium depletion, ADM did not lower aldosterone secretion in this situation suggesting that, despite having significant inhibitory effects on acutely stimulated ASR, ADM had no role in reducing chronically stimulated aldosterone. Several studies have presented evidence that the steroidogenic response of the zona glomerulosa to sodium depletion is mediated, at least in part, by AngII (Spielman \& Davis 1974, Aguilera \& Catt 1978). Also, sodium depletion, like AngII, affects aldosterone biosynthesis by altering enzyme activity at a site in both the early (Davis et al. 1966) and late (Marusic \& Mulrow 1967) biosynthetic pathway. If the above evidence is indeed true, then it is surprising that ADM failed to have an effect on aldosterone secretion stimulated by sodium depletion. The reliability of the above observations have been thrown into doubt however, with both the primacy of AngII in control of aldosterone secretion during sodium depletion challenged and the discovery of the existence of alternative biosynthetic pathways to aldosterone during sodium depletion. A number of studies have been able to show a dissociation between the renin-angiotensin system and aldosterone secretion during sodium depletion (Blair-West et al. 1971, 1973). Indeed, ADM was able to lower plasma aldosterone in sheep despite high circulating levels of renin (Charles et al. 1997). Hence, the existence of another factor, either working in concert with AngII, or overriding AngII when sodium depletion is established, cannot be discounted. This potential new factor is closely aligned with sodium status and its existence is yet to be proven beyond doubt. This factor may even be ADM itself. To further help explain the failure of ADM to inhibit aldosterone during sodium depletion, the existence of more than one basic pathway for aldosterone biosynthesis, which might come into play during sodium depletion, has 
been suggested (Muller 1980, Boon et al. 1998). The possibility of alternative steps earlier in the biosynthetic process to aldosterone bypassing any inhibitory effect ADM may be exerting on the conversion of cholesterol to pregnenolone cannot be ruled out. Another confounding variable in sodium depletion is the observed increased sensitivity of the adrenal gland, which changes the gland's normal responses to the acute stimulators (Oelkers et al. 1974). This altered behaviour of the adrenal gland and/or its agonists during sodium depletion makes it difficult to interpret findings without due consideration.

The physiological relevance of these findings is difficult to ascertain. In addition to the adrenal medulla, ADM has been reported to be present in the heart (Jougasaki et al. 1995b), and kidney (Jougasaki et al. 1995a), and to be secreted from vascular smooth muscle cells (Sugo et al. 1995) and endothelial cells (Sugo et al. 1994). Recently, ADM has been reported to be present in normal human plasma (Kitamura et al. 1994b). Hence, the possibility that ADM affects the function of the adrenal gland by acting either systemically, as a true circulating hormone, or locally, in a paracrine/autocrine fashion, arises. As noted previously, the concentration of ADM reached in the adrenal in these studies is $4 \times 10^{-9} \mathrm{~mol} / \mathrm{l}$, which is much higher than normal circulating plasma levels $\left(3 \times 10^{-15} \mathrm{~mol} / \mathrm{l}\right)$. These normal levels of ADM in human blood are too low to exert any influence on the function of the adrenal gland, so the main influence of ADM would be in pathological situations where ADM levels increase. The level of circulating ADM increased in humans where systemic and pulmonary hypertension or sodium retention had to be counteracted, although the mechanism used to achieve this remains unknown. A rise in plasma ADM level was observed in patients with hypertension and chronic renal failure (Ishimitsu et al. 1994b), primary aldosteronism (Kato et al. 1995) and chronic heart failure (Kobayashi et al. 1996). Hence, it is not inconceivable that the direct inhibitory action of ADM on aldosterone secretion may acquire relevance under pathological conditions in which aldosterone secretion is excessive and an altered fluid and electrolyte balance must be reset.

In conclusion, ADM directly inhibits acute stimulation of aldosterone by AngII, $\mathrm{KCl}$ and $\mathrm{ACTH}$, while not affecting basal and chronic stimulation by sodium depletion in vivo. ACTH-stimulated cortisol secretion was not affected. This suggests a possible role for ADM in the negative regulation of aldosterone secretion, more likely in pathological conditions characterised by excess aldosterone secretion.

\section{Acknowledgements}

We thank Richard Gogerly, Michael Stirling, David Iannello, Alan McDonald and Ruston Barlow for assist- ance with in vivo studies, and Angela Gibson for performing the plasma analyses. This work was supported by an Institute Block Grant from the National Health and Medical Research Council of Australia (Grant No. 983001).

\section{References}

Aguilera G \& Catt KJ 1978 Regulation of aldosterone secretion by the renin-angiotensin system during sodium restriction in rats. PNAS 75 4057-4061.

Aguilera G \& Catt KJ 1979 Loci of action of regulators of aldosterone biosynthesis in isolated glomerulosa cells. Endocrinology 104 1046-1052.

Andreis PG, Neri G, Prayer-Galetti T, Rossi GP, Gottardo G, Malendowicz LK \& Nussdorfer GG 1997 Effect of adrenomedullin on the human adrenal glands: An in vitro study. Journal of Clinical Endocrinology and Metabolism 82 1167-1170.

Belloni AS, Andreis PG, Rossi GP, Mingrino A, Champion HC, Kadowitz PJ, Murphy WA, Coy DH \& Nussdorfer GG $1998 a$ Inhibitory effect of adrenomedullin (ADM) on the aldosterone response of human adrenocortical cells to angiotensin-II:

Role of ADM (22-52)-sensitive receptors. Life Sciences $\mathbf{6 3}$ 2313-2321.

Belloni AS, Meneghelli V, Champion HC, Murray WA, Coy DH, Kadowitz PJ \& Nussdorfer GG 1998 b Autoradiographic evidence that zona glomerulosa and capsular vessels of the human adrenal cortex are provided with different subtypes of adrenomedullin receptors. Peptides 19 1581-1584.

Blair-West JR, Coghlan JP, Denton DA, Goding JR, Munro JA, Peterson RE \& Wintour EM 1962 Humoral stimulation of adrenal cortical secretion. Journal of Clinical Investigation 41 1606-1627.

Blair-West JR, Coghlan JP, Denton DA, Goding JR, Wintour EM \& Wright RD 1963 Control of aldosterone secretion. Recent Progress in Hormone Research 19 311-362.

Blair-West JR, Cain MD, Catt KJ, Coghlan JP, Denton DA, Funder JW, Scoggins BA \& Wright RD 1971 The dissociation of aldosterone secretion and systemic renin and angiotensin II levels during the correction of sodium deficiency. Acta Endocrinologica 66 229-247.

Blair-West JR, Coghlan JP, Cran E, Denton DA, Funder JW \& Scoggins BA 1973 Increased aldosterone secretion during sodium depletion with inhibition of renin release. American Journal of Physiology 224 1409-1414.

Boon WC, McDougall JG \& Coghlan JP 1998 Hypothesis: aldosterone is synthesised by an alternative pathway during severe sodium depletion. 'A new wine in an old bottle'. Clinical and Experimental Pharmacology and Physiology 25 369-378.

Bredt DS, Hwang PM \& Snyder SH 1990 Localization of nitric oxide synthase indicating a neural role for nitric oxide. Nature 347 768-770.

Charles CJ, Rademaker MT, Richards AM, Cooper GJS, Coy DH, Jing NY \& Nicholls MG 1997 Hemodynamic, hormonal, and renal effects of adrenomedullin in conscious sheep. American Journal of Physiology 272 R2040-R2047.

Clark BJ, Wells J, King SR \& Stocco DM 1994 The purification, cloning, and expression of a novel luteinizing hormone-induced mitochondrial protein in MA-10 mouse Leydig tumour cells. Characterisation of the steroidogenic acute regulatory protein (StAR). Journal of Biological Chemistry $26928314-28322$.

Coghlan JP, Wintour EM \& Scoggins BA 1966 The measurement of corticosteroids in adrenal vein blood of sheep. Australian Journal of Experimental Biology and Medical Science 44 639-664.

Davis WW, Burwell LR, Kelley G, Casper AG \& Bartter FC 1966 Studies of the loci of stimulation of aldosterone biosynthesis during 
sodium depletion. Biochemical and Biophysical Research Communications 22 218-222.

Ebara T, Miura K, Okumura M, Matsuura T, Kim S, Yukimura S \& Iwao H 1994 Effect of adrenomedullin on renal hemodynamics and functions in dogs. European Journal of Pharmacology 263 69-73.

Funder JW, Blair-West JR, Coghlan JP, Denton DA, Scoggins BA \& Wright RD 1969 Effect of plasma $\left[\mathrm{K}^{+}\right]$on the secretion of aldosterone. Endocrinology 85 381-384.

Gallo-Payet N, Pothier P \& Isler H 1987 On the presence of chromaffin cells in the adrenal cortex: their possible role in adrenocortical function. Biochemical and Cellular Biology 65 588-592.

Gennari C, Nami R, Agnusdei D, Maioli E \& Gonnelli S 1991 Calcitonin gene-related peptide stimulates secretion of atrial natriuretic factor in man. Journal of Hypertension 9 S252-S253.

Goding JR \& Wright RD 1964 An improved method of preparing cervical adrenal transplant in the sheep. Australian Journal of Experimental Biology and Medical Science 42 443-448.

Gogerly RL, Coghlan JP, Morgenroth P \& McDougall JG 1993 Two-compartment model of acute stimulation of aldosterone secretion in vivo by angiotensin II. American Journal of Physiology 264 E456-E464.

Hall PF, Charpponnier C, Nakamura M \& Gabbiani G 1979 The role of microfilaments in the response of adrenal tumour cells to adrenocorticotrophic hormone. Journal of Biological Chemistry 254 9080-9084.

Hinson JP \& Kapas S 1998 The role of endothelial cell products in the regulation of adrenocortical function: actions of endothelin, nitric oxide, adrenomedullin and PAMP. Hormone and Metabolism Research 30 334-340.

Ichiki Y, Kitamura K, Kangawa K, Kawamoto M, Matsuo H \& Eto T 1995 Distribution and characterisation of immunoreactive adrenomedullin in porcine tissue, and isolation of adrenomedullin[26-52] and adrenomedullin[34-52] from porcine duodenum. Journal of Biochemistry 118 765-770.

Ishimitsu T, Kojima M, Kangawa K, Hino J, Matsuoka H, Kitamura K, Eto T \& Matsuo H 1994a Genomic structure of human adrenomedullin gene. Biochemical and Biophysical Research Communications 203 631-639.

Ishimitsu T, Nishikimi T, Saito Y, Kitamura K, Eto T, Kangawa K, Matsuo H, Omae T \& Matsuoka H $1994 b$ Plasma levels of adrenomedullin, a newly identified hypotensive peptide, in patients with hypertension and renal failure. Journal of Clinical Investigation $942158-2161$.

Ishiyama Y, Kitamura K, Ichiki Y, Nakamura S, Kida O, Kangawa K \& Eto T 1993 Hemodynamic effects of a novel hypotensive peptide, human adrenomedullin, in rats. European Journal of Pharmacology 241 271-273.

Jougasaki M, Wei CM, Aarhus LL, Heublein DM, Sandberg SM \& Burnett JC Jr 1995a Renal localisation and actions of adrenomedullin: a natriuretic peptide. American Journal of Physiology 268 F657-F663.

Jougasaki M, Wei CM, Heublein DM, Sandberg SM \& Burnett JC Jr $1995 b$ Immunohistochemical localisation of adrenomedullin in canine heart and aorta. Peptides 16 773-775.

Kapas S \& Clark AJL 1995 Identification of an orphan receptor gene as a type I calcitonin gene-related peptide receptor. Biochemical and Biophysical Research Communications 217 832-838.

Kapas S \& Hinson JP 1996 Actions of adrenomedullin on the rat adrenal cortex. Endocrine Research 22 861-865.

Kapas S, Catt KJ \& Clark AJL 1995 Cloning and expression of cDNA encoding a rat adrenomedullin receptor. Journal of Biological Chemistry 270 25344-25347.

Kapas S, Martinez A, Cuttitta F \& Hinson JP 1998 Local production and action of adrenomedullin in the rat adrenal zona glomerulosa. Journal of Endocrinology 156 477-484.
Kato J, Kitamura K, Kuwasako K, Tanaka M, Ishiyama Y, Shimokubo T, Ichiki Y, Nakamura S, Kangawa T \& Eto T 1995 Plasma adrenomedullin in patients with primary aldosteronism. American Journal of Hypertension 8 997-1000.

Katoh F, Niina H, Kitamura K, Ichiki Y, Yamamoto Y, Kangawa K, Eto T \& Wada A $1994 \mathrm{Ca}(2+)$-dependent cosecretion of adrenomedullin and catecholamines mediated by nicotinic receptors in bovine cultured adrenal medullary cells. FEBS Letters 348 61-64.

Kitamura K, Kangawa K, Kawamoto M, Ichiki Y, Nakamura S, Matsuo H \& Eto T 1993 Adrenomedullin: a novel hypotensive peptide isolated from human pheochromocytoma. Biochemical and Biophysical Research Communications 192 553-560.

Kitamura K, Sakata J, Kangawa K, Kojima M, Matsuo H \& Eto T $1994 a$ Cloning and characterisation of cDNA encoding a precursor for human adrenomedullin. Biochemical and Biophysical Research Communications 194 720-725.

Kitamura K, Ichiki Y, Tanaka M, Kawamoto M, Emura J, Sakakibara S, Kangawa K, Matsuo H \& Eto T $1994 b$ Immunoreactive adrenomedullin in human plasma. FEBS Letters 341 288-290.

Kobayashi K, Kitamura K, Etoh T, Nagatomo Y, Takenaga M, Ishikawa T, Imamura T, Koiwaya Y \& Eto T 1996 Increased plasma adrenomedullin levels in chronic congestive heart failure. American Heart Journal 131 994-998.

Kohno M, Kano H, Horio T, Yokokawa K, Yasunari K \& Takeda T 1995 Inhibition of endothelin production by adrenomedullin in vascular smooth muscle cells. Hypertension 25 1185-1190.

Lainchbury JG, Cooper GJS, Coy DH, Jing NY, Lewis LK, Yandle TG, Richards AM \& Nicholls MG 1997 Adrenomedullin: a hypotensive hormone in man. Clinical Science 92 467-472.

Marusic ET \& Mulrow PJ 1967 Stimulation of aldosterone biosynthesis in adrenal mitochondria by sodium depletion. Journal of Clinical Investigation 46 2101-2108.

Mazzocchi G, Musajo F, Neri G, Gottardo G \& Nussdorfer GG 1996a Adrenomedullin stimulates steroid secretion by the isolated perfused rat adrenal gland in situ: Comparison with calcitonin gene-related peptide effects. Peptides 17 853-857.

Mazzocchi G, Rebuffat P, Gottardo G \& Nussdorfer GG 1996 b Adrenomedullin and calcitonin gene-related peptide inhibit aldosterone secretion in rats, acting via a common receptor. Life Sciences 58 839-844.

McLatchie LM, Fraser NJ, Main MJ, Wise A, Brown J, Thompson N, Solari R, Lee MG \& Foord SM 1998 RAMPs regulate the transport and ligand specificity of the calcitoninreceptor-like-receptor. Nature 393 333-339.

Muller J 1980 The conversion of 18-hydroxycorticosterone and 18-hydroxy-11-deoxycorticosterone to aldosterone by rat adrenal tissue: evidence for an alternate biosynthetic pathway. Journal of Steroid Biochemistry 13 245-251.

Natarajan R, Lanting L, Bai W, Bravo EL \& Nadler J 1997 The role of nitric oxide in the regulation of aldosterone synthesis by adrenal glomerulosa cells. Journal of Steroid Biochemistry and Molecular Biology $6147-53$.

Nussdorfer GG 1996 Paracrine control of adrenal cortical function by medullary chromaffin cells. Pharmacological Reviews 48 495-530.

Nussdorfer GG, Rossi GP, Malendowicz LK \& Mazzocchi G 1999 Autocrine-paracrine endothelin system in the physiology and pathology of steroid secreting tissues. Pharmacological Reviews $\mathbf{5 1}$ 403-438.

Oelkers W, Brown JJ, Fraser R, Lever AF, Morton JJ \& Robertson JI 1974 Sensitisation of the adrenal cortex to angiotensin II in sodium-deplete man. Circulation Research 40 69-77.

Parkes DG \& May CN 1995 ACTH-suppressive and vasodilator actions of adrenomedullin in conscious sheep. Journal of Neuroendocrinology 7 923-929.

Richards AM, Nicholls MG, Lewis L \& Lainchbury JG 1996 Adrenomedullin. Clinical Science 91 3-16. 
Sakata J, Shimokubo T, Kitamura K, Nishizono M, Iehiki Y, Kangawa K, Matsuo M \& Eto T 1994 Distribution and characterisation of immunoreactive rat adrenomedullin in tissue and plasma. FEBS Letters 352 105-108.

Samson W, Murphy T \& Schell D 1995 A novel vasoactive peptide, adrenomedullin, inhibits pituitary adrenocorticotropin release. Endocrinology 136 2349-2352.

Shimekake Y, Nagata K, Ohta S, Kambayashi Y, Teraoka H, Kitamura K, Eto T, Kangawa K \& Matsuo H 1995 Adrenomedullin stimulates two signal transduction pathways, cAMP accumulation and $\mathrm{Ca}^{2+}$ mobilisation, in bovine aortic endothelial cells. Journal of Biological Chemistry 270 4412-4417.

Simmons JC \& Freeman RH 1995 L-arginine analogues inhibit aldosterone secretion in rats. American Journal of Physiology 265 R1137-R1142.

Spielman WS \& Davis JO 1974 The renin-angiotensin system and aldosterone secretion during sodium depletion in the rat. Circulation Research 35 615-624.

Sugo S, Minamino N, Kangawa K, Miyamoto M, Kitamura K, Sakata J, Eto T \& Matsuo H 1994 Endothelial cells actively synthesise and secrete adrenomedullin. Biochemical and Biophysical Research Communications 201 1160-1166.

Sugo S, Minamino N, Shoji H, Kangawa K, Kitamura K, Eto T \& Matsuo H 1995 Interleukin-1, tumour necrosis factor and lipopolysaccharide additively stimulate production of adrenomedullin in vascular smooth muscle cells. Biochemical and Biophysical Research Communications 207 25-32.
Tangalakis K, Roberts FE \& Wintour EM 1992 The time-course of ACTH stimulation of cortisol synthesis by the immature ovine foetal adrenal gland. Journal of Steroid Biochemistry and Molecular Biology 42 527-532.

Vinson GP, Hinson JP \& Raven PW 1985 The relationship between tissue preparation and function; methods for the study of control of aldosterone secretion: A review. Cellular and Biochemical Functions $\mathbf{3}$ 235-253.

Yamaguchi T, Baba K, Doi Y \& Yano K 1995 Effect of adrenomedullin on aldosterone secretion by dispersed rat adrenal zona glomerulosa cells. Life Sciences 56 379-387.

Yamaguchi T, Baba K, Doi Y, Yano K, Kitamura K \& Eto T 1996 Inhibition of aldosterone production by adrenomedullin, a hypotensive peptide, in the rat. Hypertension 28 308-314.

Yamamoto A, Kimura S, Hasui K, Fujisawa Y, Tamaki T, Fukui K, Iwao H \& Abe Y 1988 Calcitonin gene-related peptide (CGRP) stimulated the release of atrial natriuretic peptide (ANP) from isolated rat atria. Biochemical and Biophysical Research Communications 155 1452-1458.

Yokoi H, Arima H, Murase T, Kondo K, Iwasaki Y \& Oiso Y 1996 Intracerebroventricular injection of adrenomedullin inhibits vasopressin release in conscious rats. Neuroscience Letters 216 65-67.

Received 23 September 1999

Revised manuscript received 28 February 2000 Accepted 28 March 2000 